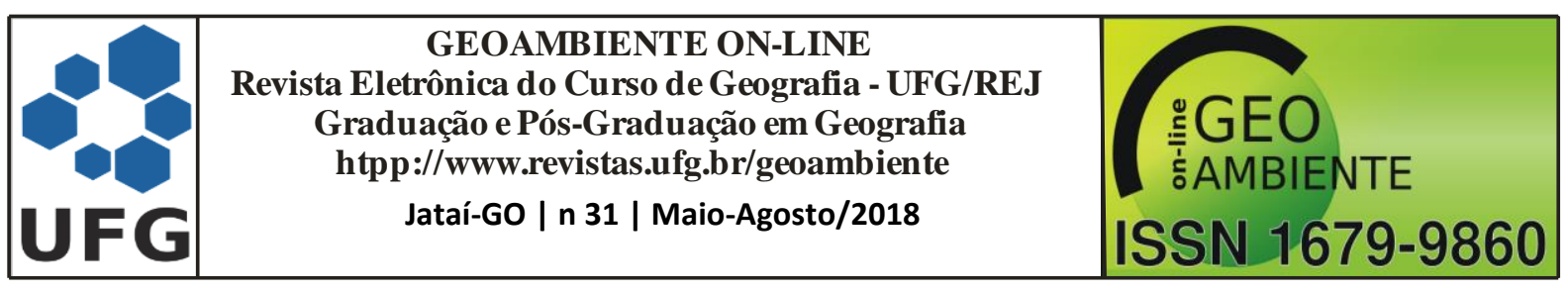

\title{
USO DE TÉCNICAS PEDOMÉTRICAS NA PREDIÇÃO E MAPEAMENTO DIGITAL DO POTENCIAL NATURAL A EROSÃO DOS SOLOS
}

\begin{abstract}
Vanderley Severino Santos ${ }^{1}$, Reinaldo Lorandi ${ }^{2}$, Carlos Wilmer Costa ${ }^{3}$
(1 - Instituto Federal de Educação, Ciências e Tecnologia de Mato Grosso, Docente, Doutor em Ecologia, vanderley.santos@cba.ifmt.edu.br, 2 - Universidade Federal de São Carlos, Docente, lorandir@gmail.com, 3 - Universidade Federal de São Carlos, Doutorando em Ciências Ambientais, carloswilmercosta@gmail.com)
\end{abstract}

Resumo: A Equação Universal de Perdas de Solos é um modelo paramétrico utilizado na predição da média anual de perdas de solos por erosão laminar, porém, este modelo é relativamente simples. O sensoriamento remoto e suas técnicas de observação do ambiente estimularam estudos ligados à distribuição espacial das diferentes classes e propriedades do solo. Essas técnicas também podem ser aplicadas no mapeamento dos processos da dinâmica superficial que modelam a superfície terrestre. Este trabalho teve como objetivo propor, avaliar e analisar o emprego de técnicas pedométricas de mapeamento digital dos solos na construção de um modelo preditivo, alternativo ao modelo EUPS, para ser empregado no mapeamento do potencial natural de erosão (PNE) das terras da bacia dos córregos Amaral e Brilhante em Jaciara-MT. Os resultados mostram que com o uso dessa técnica foi possível construir por meio de regressão-krigagem um novo mapa com estimativas do Potencial Natural a Erosão. Nesse mapa verificou-se um equilíbrio quantitativo na distribuição das áreas com potencial natural a erosão inferior a $600 \mathrm{t} \mathrm{ha-}^{1}$ ano-$^{1} \mathrm{e}$ áreas com potencial entre $600 \mathrm{a}$ $1200 \mathrm{t} \mathrm{ha}^{1}$ ano-1 $^{1}\left(134,88 \mathrm{~km}^{2}\right.$ e $141,73 \mathrm{~km}^{2}$, respectivamente). Enquanto no mapa confeccionado pelo método tradicional (EUPS) verificou-se predomínio de áreas com potencial natural a erosão inferiores a 600 t.ha- $^{1} \cdot$ ano-$^{1}\left(205,37 \mathrm{~km}^{2}\right)$.

Palavras-chave: Erosão, covariáveis ambientais, Mineração de dados.

Artigo recebido para publicação em 30 de Junho de 2017

Artigo aprovado para publicação em 18 de Maio de 2018 


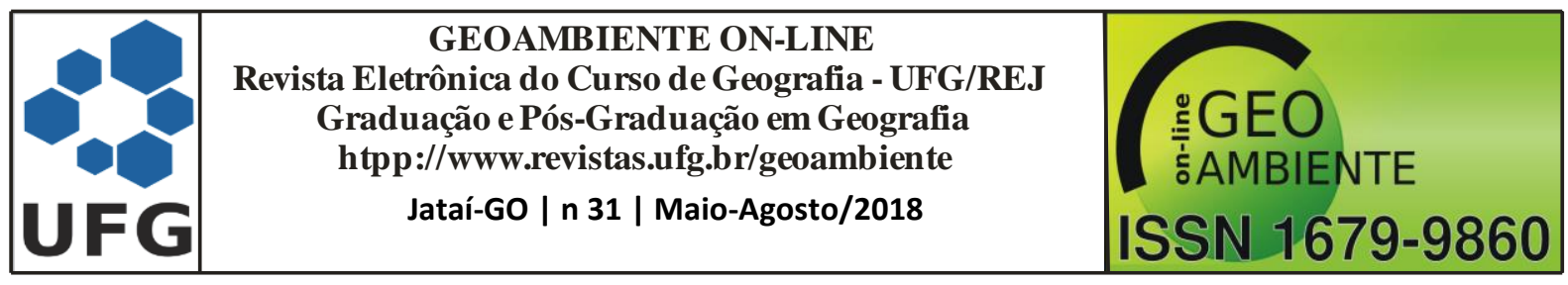

\title{
USE OF PEDOMETRIC TECHNIQUES IN THE PREDICTION AND DIGITAL MAPPING OF NATURAL POTENTIAL TO SOIL EROSION
}

\begin{abstract}
The Universal Soil Loss Equation is a parametric model widely used in the prediction of annual average soil loss by laminar erosion, however, this model it is relatively simple. Remote sensing and its techniques of observation of the environment stimulated studies related to the spatial distribution of the different classes and properties of the soil. These techniques can be applied to map the surface dynamics processes that shape the Earth's surface. The objective of this work was to propose, evaluate and analyze the use of pedometric techniques applied to soils digital mapping for building a predictive model, other than the EUPS model, to be used in the mapping of the natural potential of soil erosion (PNE) of the Amaral and Brilhante basins in Jaciara-MT. The results show that it was possible, using this technique, to construct a new map with estimates for the Natural Potential to Erosion by means of regression-kriging. In this map we found a quantitative balance between the distribution of areas with natural erosion potential of less than $600 \mathrm{t} \mathrm{ha}^{-1}$ year-1 and areas with losses between 600 and $1200 \mathrm{t} \mathrm{ha}^{-1}$ year-1 $\left(134.88 \mathrm{~km}^{2}\right.$ and $141.73 \mathrm{~km}^{2}$ respectively). Whereas in the map made by the traditional method (EUPS) there was a predominance of areas with natural erosion potential of less than $600 \mathrm{t} \mathrm{ha}^{-1}$ year- ${ }^{1}\left(205,37 \mathrm{~km}^{2}\right)$.
\end{abstract}

Keywords: Erosion, Environmental covariates, Data Mining.

\section{UTILISATION DES TECHNIQUES PEDOMETRIQUES DANS LA PRÉDICTION ET LA CARTOGRAPHIE NUMÉRIQUE DU POTENTIEL NATUREL À L'EROSION DU SOL}

Résumé: L'équation universelle de perte de sol est un modèle paramétrique utilisé dans la prédiction de la perte moyenne annuelle de sol par érosion laminaire, ce modele c'est relativement simple. La télédétection et ses techniques d'observation de l'environnement ont stimulé des études liées à la distribution spatiale des différentes classes et propriétés du sol. Ces techniques peuvent être appliquées pour cartographier les processus de dynamique de surface qui façonnent la surface de la Terre. L'objectif de ce travail était de proposer, évaluer et analyser l'utilisation des techniques pédométriques appliquées à la cartographie numérique 


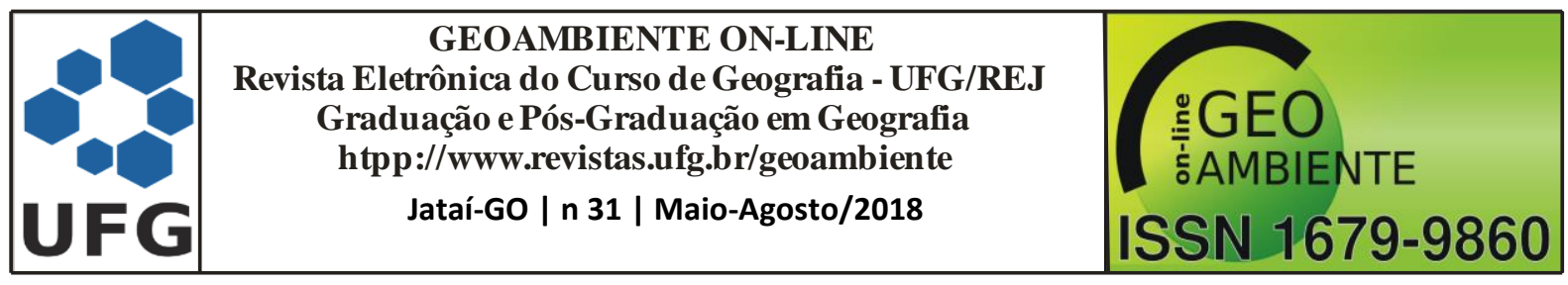

des sols pour construire un modèle prédictif, autre que le modèle EUPS, pour être utilisé dans la cartographie du potentiel naturel d'érosion des sols (PNE) Des bassins Amaral et Brilhante à Jaciara-MT. Les résultats montrent qu'il était possible, en utilisant cette technique, de construire une nouvelle carte avec des estimations du potentiel naturel à l'érosion au moyen de la régression-krigeage. Dans cette carte, nous avons trouvé un équilibre quantitatif entre la répartition des zones avec un potentiel d'érosion naturel de moins de $600 \mathrm{t} \mathrm{ha}^{-1} \mathrm{an}^{-1}$ et des zones de pertes comprises entre 600 et $1200 \mathrm{t} \mathrm{ha}^{-1}$ an- ${ }^{1}\left(134,88 \mathrm{~km}^{2}\right.$ et $141,73 \mathrm{~km}^{2}$ respectivement). Alors que dans la carte réalisée par la méthode traditionnelle (EUPS), il y avait une prédominance de zones avec un potentiel d'érosion naturel de moins de $600 \mathrm{t}$ ha-1 an- $^{1}\left(205,37 \mathrm{~km}^{2}\right)$.

Mots-clés: Erosion, covariables environnementaux, Data Mining.

\section{Introdução}

A EUPS (Equação Universal de Perdas de Solos) foi proposta por Wischmeier e Smith (1978) para estimativa das perdas de solo por erosão hídrica. Segundo Bueno e Stein (2004) a EUPS é um modelo paramétrico usado no mundo todo para a predição das perdas médias anuais de solos por erosão laminar, porém, apresenta limitações científicas em função de sua relativa simplicidade.

A EUPS é uma equação empírica composta por fatores de cunho natural e antrópico. Esta equação pode ser aplicada parcialmente, sem considerar os fatores cobertura vegetal e técnicas conservacionistas empregadas na produção (ACCIOLY et al., 2010). Conhecendo os valores de erosividade, erodibilidade, comprimento de rampas e declividade pode-se estimar para um local o seu Potencial Natural à Erosão (PNE).

Os resultados da aplicação da EUPS podem ser essenciais para a identificação de áreas com diferentes graus de suscetibilidade a erosão e a compreender os mecanismos erosivos, bem como, suas causas e efeitos. Porém, esse modelo de predição de erosão, se justifica quando a base de dados e demais informações cartográficas para este fim, são limitadas. 


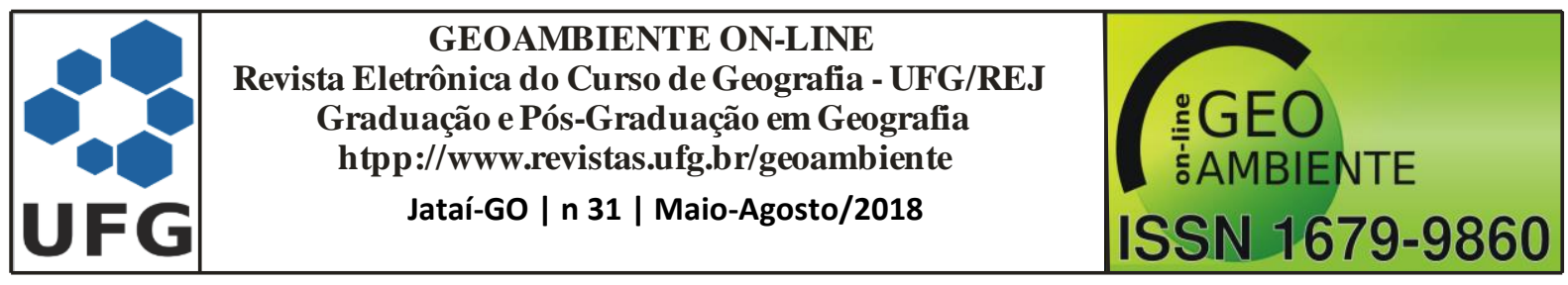

Com o avanço do sensoriamento remoto existe uma disponibilidade considerável de dados espaciais que podem ser explorados por várias áreas do conhecimento. Por exemplo, há algumas técnicas pedométricas que reúnem modelagem quantitativa e geotecnologias que são empregadas no mapeamento digital dos solos. Ten Caten et al. (2011) afirmam que o sensoriamento remoto possibilitou desenvolver várias técnicas de observação do ambiente que estimularam estudos ligados à distribuição espacial das classes e propriedades do solo.

Os modelos digitais de elevação (MDE) oriundos do SRTM (Shuttle Radar Topography Mission) e demais imagens de sensoriamento remoto são fontes de variáveis ambientais preditoras para uso no mapeamento digital de solos (MDS).

A pedologia quantitativa, ou pedometria, apresenta técnicas e métodos de mapeamento digital de solos. A pedometria pressupõe que a matemática e os métodos numéricos e estatísticos podem equacionar a complexidade e o desconhecimento das propriedades e processos intrínsecos do solo (McBRATNEY, et al., 2000).

O mapeamento digital de solos pode ser interpretado como o estabelecimento de relações matemáticas que ligam o solo às covariáveis ambientais (McBRATNEY, et al., 2003), então, por que não utilizar técnicas pedométricas no mapeamento dos processos de dinâmica superficial que modelam a superfície terrestre, uma vez que, métodos quantitativos multivariados e geotecnologias têm sido cada vez mais utilizados para caracterizar e mapear aspectos ambientais.

Segundo Campos (2012) conhecimentos de superfícies geomórficas, unidades de vertentes e curvatura do terreno, tradicionais em estudos de solo-paisagem, também se enquadram para uso na obtenção de informações de estimativas de erosão, estabelecimento de manejo e planejamento e uso do solo.

Visando contribuir com estudos, que auxiliam na compreensão dos processos erosivos e que identifiquem os riscos ambientais, este trabalho teve como objetivo, propor, avaliar e analisar o emprego de técnicas pedométricas de mapeamento digital dos solos na construção de um modelo preditivo alternativo para o mapeamento do potencial natural à erosão das terras da bacia dos córregos Amaral e Brilhante em Jaciara-MT. 


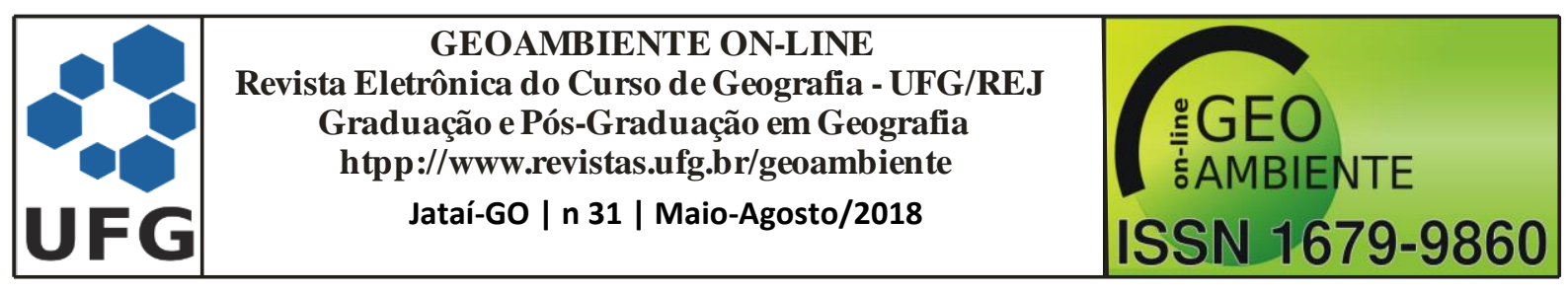

Caracterização ambiental da área investigada

A área de estudo está localizada na borda norte do pantanal de Mato Grosso, abrange a bacia hidrográfica dos Córregos Amaral e Brilhante, que formam o Rio Tenente Amaral, afluente do São Lourenço, o qual está inserido na bacia do Cuiabá/Paraguai/Paraná. Situa-se no município de Jaciara, no Centro-Sul do Estado, entre as coordenadas geográficas: $15^{\circ} 48^{\prime} \mathrm{S}$ a $16^{\circ} 00^{\prime}$ S e $55^{\circ} 00^{\prime} \mathrm{W}$ a $55^{\circ} 20^{\prime} \mathrm{W}$, localização compatível com a folha SD-21-Z-D-IV-4, em uma área de aproximadamente $339,56 \mathrm{~km}^{2}$ e perímetro alcançando 75,5 km (Figura 1).

Figura 1. Mapa de localização da bacia hidrográfica dos Córregos Amaral e Brilhante.

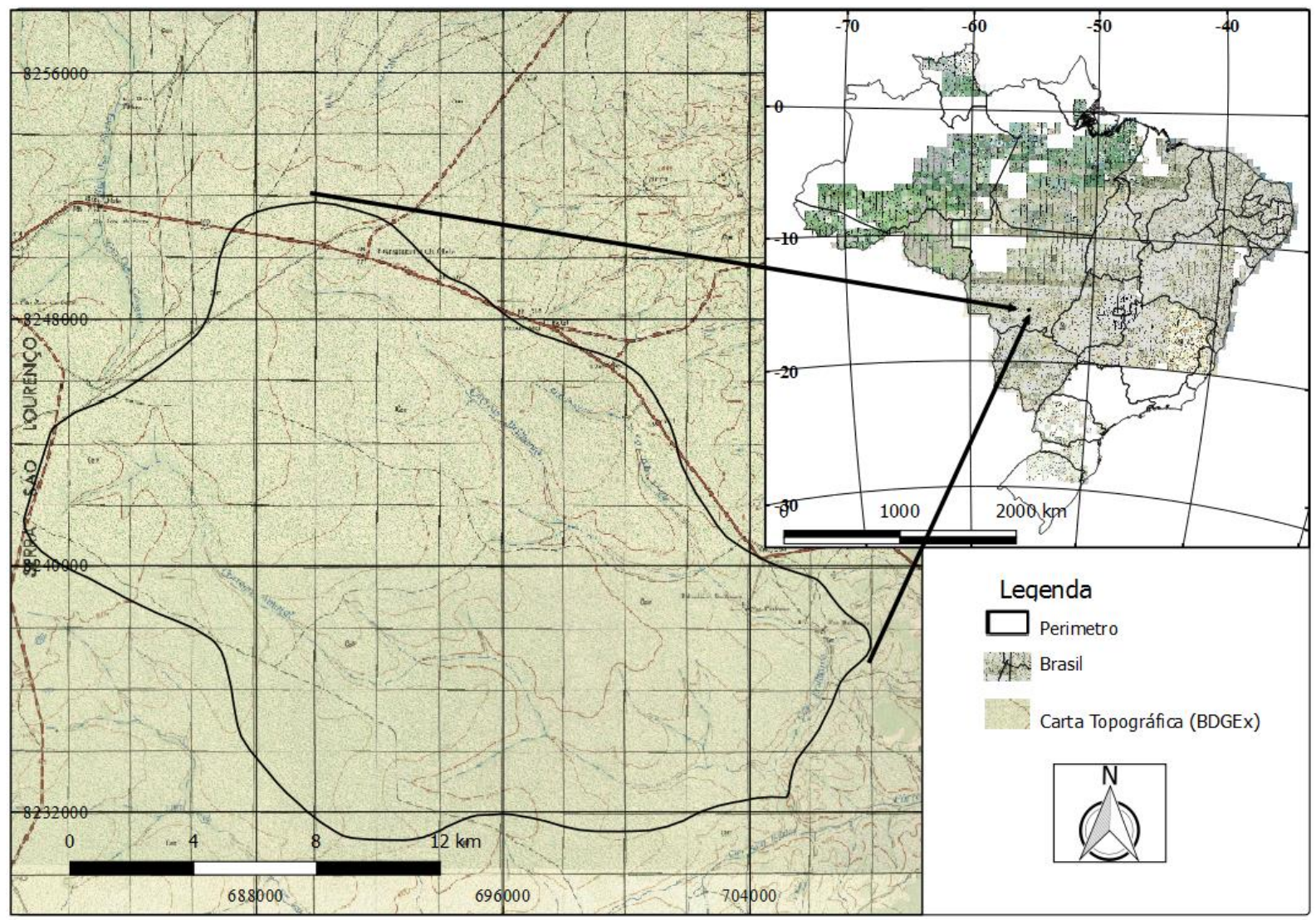

Elaboração: Próprio autor

A nascente principal do Córrego Brilhante encontra-se nas coordenadas $15^{\circ} 49^{\prime} 46.37^{\prime}$ S e $55^{\circ} 13^{\prime} 59.09^{\prime} \mathrm{W}$ e a do Córrego Amaral nas coordenadas $15^{\circ} 54^{\prime} 0.22^{\prime} \mathrm{S}$ e $55^{\circ} 18^{\prime} 17.44 ”$ W.

Com base no método de Strahler de hierarquização da rede de drenagem, a bacia hidrográfica enquadra-se como de $4^{\text {a }}$ (quarta) ordem. 


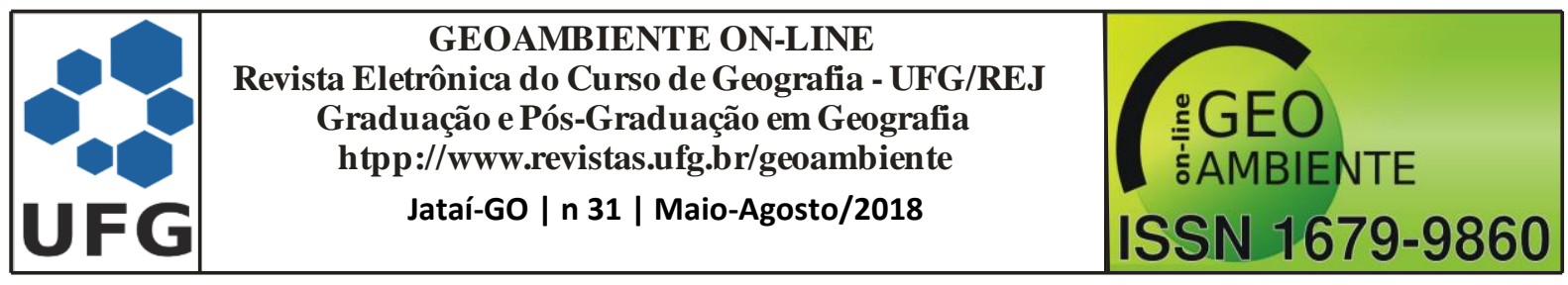

O padrão de drenagem na bacia é subdendrítico com vales em "V" abertos ou mesmo planos, padrão típico desenvolvido sobre rochas de resistência uniforme, ou em estruturas sedimentares horizontais (CHRISTOFOLETTI, 1980).

A região onde está inserida apresenta relevos característicos das Unidades Geomorfológicas Planalto dos Guimarães, a altimetria varia entre 400 a 800m. A densidade dos rios é 0,06 rios por $\mathrm{Km}^{2}$ e a densidade de drenagem é muito baixa $\left(0,45 \mathrm{Km} / \mathrm{Km}^{2}\right)$. As porções norte, central, sul e sudoeste da bacia; apresenta topos planos a tabulares, vertentes longas e retilíneas e em alguns locais são levemente convexas. Ocorre sistema de superfícies de dissecação estrutural com fraco aprofundamento das incisões em manchas isoladas no extremo oeste da bacia.

Considerando uma escala de abrangência continental, a área de estudo se insere no domínio geológico Cobertura Fanerozóica (inclusive na província subandina) e na compartimentação geotectônica Cráton Paraná correspondente a Província Estrutural do Paraná (HASUI, 2012). Considerando uma escala mais detalhada, distribuem-se pela bacia hidrográfica as unidades geológicas de terrenos sedimentares, descritas na Tabela 1.

O plantio de cana-de-açúcar predomina na bacia, verificam-se, também pastagens e cultivos de soja, milho, sorgo e milheto.

A vegetação é composta por formações Savânicas (Arborizadas; Florestadas; Parque e Gramíneo-Lenhosa) e também por formações Florestais (Estacional Semidecidual; Hidrófila e de Galeria).

Conforme o Sistema Brasileiro de Classificação de Solos - SIBCS (EMBRAPA, 1999), verifica-se que na área a cobertura pedológica é constituída pelas classes de solos: LATOSSOLOS VERMELHOS Ácricos; LATOSSOLOS VERMELHOS Distróficos; LATOSSOLOS VERMELHO - AMARELOS Distróficos; LATOSSOLOS AMARELOS Distróficos; PLINTOSSOLOS ARGILÚVICOS Distróficos; PLINTOSSOLOS PÉTRICOS Concrecionários Distróficos; GLEISSOLOS HÁPLICOS Tb Distróficos; NEOSSOLOS QUARTZARÊNICOS Hidromórficos; NEOSSOLOS QUARTZARÊNICOS Órticos; ORGANOSSOLOS FÓLICOS Fíbricos e AFLORAMENTOS ROCHOSOS. 


\begin{tabular}{|c|c|c|}
\hline & $\begin{array}{c}\text { GEOAMBIENTE ON-LINE } \\
\text { Revista Eletrônica do Curso de Geografia - UFG/REJ } \\
\text { Graduação e Pós-Graduação em Geografia } \\
\text { htpp://www.revistas.ufg.br/geoambiente } \\
\text { Jataí-Go | n } 31 \text { | Maio-Agosto/2018 }\end{array}$ & $\begin{array}{c}\text { : GEO } \\
\text { G.AMBIENTE } \\
\text { G }\end{array}$ \\
\hline
\end{tabular}

Tabela 1. Unidades litoestratigráficas reconhecidas na área de estudo.

\begin{tabular}{lll}
\hline $\begin{array}{l}\text { Unidade/ } \\
\text { Grupo }\end{array}$ & Era \& Período & Descrição \\
\hline & Cenozóica & $\begin{array}{l}\text { Formada por arenitos argilosos amarelados e } \\
\text { avermelhados, parcialmente laterizados médios a } \\
\text { grossos, argilosos e níveis de conglomerados, além de } \\
\text { Cachoeirinha }\end{array}$ \\
& Terciário & $\begin{array}{l}\text { argilito cinza-esverdeado. } \\
\end{array}$
\end{tabular}

Formação

Ponta Grossa/ Paleozóica

Constituída por folhelhos carbonosos marinhos de cor

Paraná Devoniano
cinza e intercalações de arenitos finos (síltico e pelito) depositados sob a ação de ondas em uma plataforma rasa.

$\begin{array}{ll}\text { Formação } & \text { Paleozóica } \\ \text { Furnas/ } & \text { Devoniano } \\ \text { Paraná } & \end{array}$

Composta regionalmente por arenitos grossos imaturos a muito grossos com estratificação cruzada planar, com ocorrência subordinada de arenitos grossos a muito grossos com estratificação cruzada acanalada e arenitos finos a médios com estratificação cruzada hummocky.

Fonte: Lacerda Filho et al. (2004).

Segundo Nimer (1989), o clima local apresenta temperatura média anual de $22 \mathrm{C}^{\mathrm{o}}$, e altura média de precipitação anual entre $1.500 \mathrm{~mm}$ a $1.750 \mathrm{~mm}$ com duas estações: uma chuvosa, de setembro a abril e outra seca de maio a agosto. Conforme Nimer (1989), de acordo com o modelo de classificação climática de W. Köeppen de 1918 o clima do local se enquadra como do tipo tropical chuvoso de savana (Aw).

\section{Material e métodos}

O método adotado, neste trabalho, para estimar o potencial natural a erosão, é o mesmo que é utilizado no mapeamento digital de solos, o qual foi apresentado no curso a distância "cartografia digital de solos", ofertado através da plataforma de ensino à distância da Embrapa Solos, e se encontra descrito em Mendonça-Santos e Santos, (2003), Vasques et al. (2013) e em Baca et al. (2013). 


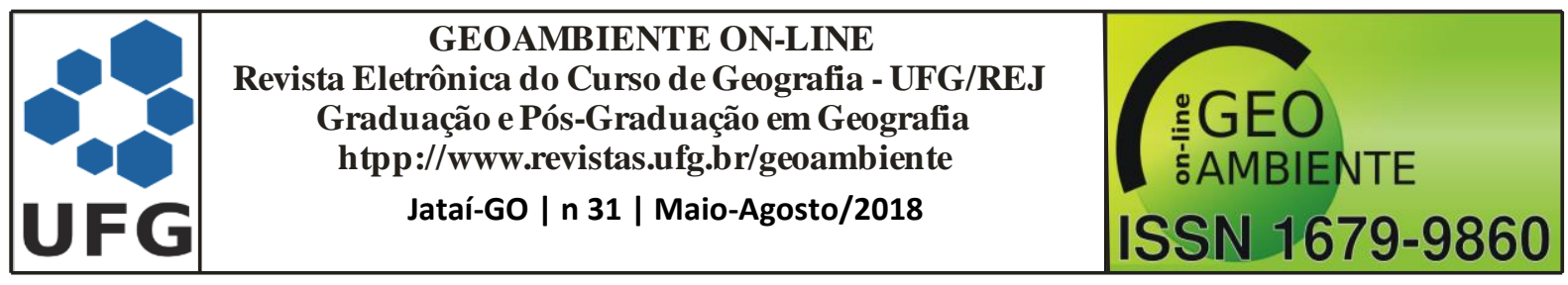

Além dos levantamentos de campo e análises de solos, esse método utiliza dados obtidos remotamente em plataformas espaciais e a matemática para produzir informações dos recursos naturais (ANDRADE e MENDONÇA-SANTOS 2016).

As amostras do potencial natural à erosão (PNE/EUPS) foram extraídas de um mapa produzido por meio da aplicação parcial da Equação Universal de Perdas de Solos. Para produzir este mapa, dados de erosividade $(\mathrm{R})$, erodibilidade $(\mathrm{K})$, declividade e comprimento de rampas (LS) do local foram aplicados conforme indicado na Eq. (01):

$P N E=R . K . L S$

Os valores de erosividade das chuvas expresso em MJ mm ha- ${ }^{1} \mathrm{~h}^{-1}$, foram calculados usando dados de precipitações cedidos pela administração da Usina Pantanal, esses dados foram obtidos em onze pluviômetros instalados na área e mais os dados de uma estação do Instituto Nacional de Meteorologia (Estação São Vicente). A erosividade média mensal foi estimada conforme Bertone e Lombardi Neto (2005) aplicando a Eq. (02):

$R=67,355\left(r^{2} / P\right)^{0,85}$

Onde: $\mathrm{R}=$ Erosividade da chuva; $\mathrm{r}=$ Precipitação média mensal $(\mathrm{mm}) ; \mathrm{P}=$ Precipitação média anual $(\mathrm{mm})$.

A partir da interpolação (média ponderada pela distância) as médias mensais de erosividade da bacia foram espacializadas. Com a soma das doze cartas de erosividade média mensal gerou a carta com a média anual de erosividade da bacia.

O mapa pedológico da área, produzido e publicado na escala 1:50.000 por FEMA (1999), foi convertido para o formato digital. Conforme indicado por Brasil (1997), Salomão (1999) e Fonseca Neto, Salomão e Castro Júnior (2002), correlacionou-se as diferentes classes de solos desse mapa aos seus correspondentes índices relativos de erodibilidade. Posteriormente, de acordo com Silva et al. (2003) esses índices de erodibilidade foram convertidos em tha $\mathrm{MJ}^{-1} \mathrm{~mm}^{-1}$.

A declividade (\%) e o comprimento de rampas (metros) foram extraídos do modelo digital de elevação (DEM) disponibilizado pelo projeto Topodata - Banco de dados geomorfométricos do Brasil. 


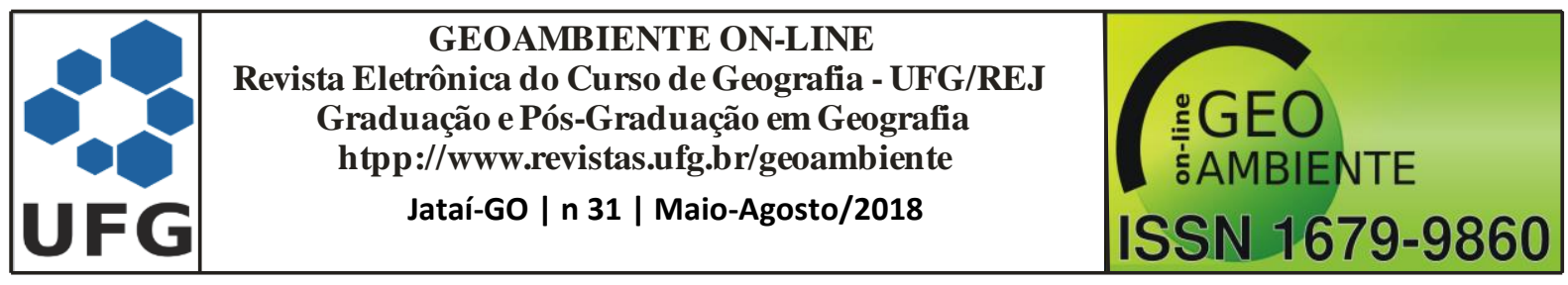

A partir do DEM também se obteve as covariáveis ambientais derivadas do relevo. As imagens do Landsat 8 bandas 2,3,4,5,6 e 7 datadas de maio de 2016 também compõem o rol das covariáveis ambientais usadas como regressoras ou independentes para gerar o modelo, inclusive o Índice de Vegetação por Diferença Normalizada (NDVI) calculado usando essas imagens, aplicando-se a Eq. (03):

$N D V I=N I R-R / N I R+R$

Onde, NDVI é o índice de Vegetação por Diferença Normalizada; NIR é a refletância no comprimento de onda correspondente ao Infravermelho Próximo; R é a refletância no comprimento de onda do Vermelho.

Um arquivo shapefile com 97 pontos, distribuídos de forma sistemática sobre os nós de uma malha georreferenciada e regularmente espaçadas $(4 \mathrm{~km})$ foi gerado e utilizado para a extração das amostras da variável resposta (PNE/EUPS) e das variáveis independentes (covariáveis ambientais).

Conforme está descrito em Mendonça-Santos e Santos, (2003), Baca et al. (2013) e em Vasques et al. (2013) o novo mapa com a estimativa do PNE foi gerado em três etapas a partir das 97 observações de treinamento extraídas da variável resposta (PNE/EUPS) e das covariáveis ambientais (variáveis independentes) através de regressão-krigagem.

Na primeira etapa, denominada de modelagem da tendência global, o PNE/RLM foi predito através de regressão linear múltipla em função das covariáveis ambientais, nesta etapa, optou-se pelo uso do software WEKA 3.8.0.

Na segunda etapa, denominada de modelagem da tendência local, usando o software R (interface RStudio), os resíduos da regressão gerados na etapa anterior foram interpolados através de krigagem ordinária pontual. Para a produção do mapa com os resíduos, a existência de autocorrelação espacial foi verificada, ajustada e confirmada no semivariograma.

$\mathrm{Na}$ terceira etapa, novamente usando o software SAGA, o novo mapa com a estimativa do PNE/RLM foi produzido empregando a equação de regressão gerada na primeira etapa e, por fim, este mapa foi somado ao mapa de resíduos krigados produzido na segunda etapa. 


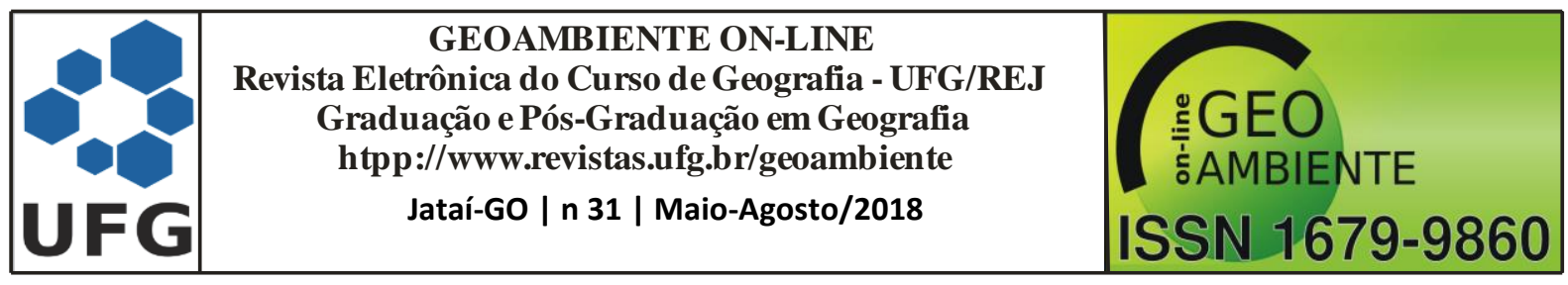

Para a execução deste trabalho foram utilizados os softwares QGIS 2.8, SAGA 2.0.8(SAGA User Group Association, 2012) para geoprocessamento, o Weka 3.8 e o R 3.3.2 (R Core Team, 2016) implementado através RStudio 1.0.136 (RStudio, 2016) para as análises estatísticas e planilhas eletrônicas para algumas conversões de arquivo e confirmações de cálculos estatísticos.

Todos os componentes do banco de dados apresentam resolução de 30 metros e projeção Universal Transverso de Mercator fuso 21 sul, Datum SIRGAS2000.

\section{Resultados e discussão}

Para a manipulação dos dados um banco de dados foi implementado no SAGA GIS. Este banco foi composto inicialmente pelas camadas: Pontos97amostras, DEM, L8maio16B2, L8maio16B3, L8maio16B4, L8maio16B5, L8maio16B6 e L8maio16B7. Posteriormente, importaram-se as camadas geradas no QGIS (erosividade e erodibilidade).

Em seguida, usando a equação (02) e as bandas 4 e 5 do Landsat 8 (L8maio16B4 e L8maio16B5) foi produzida a camada denominada Normalized Difference Vegetation Index. $\mathrm{Na}$ sequência, extraíram-se do DEM as camadas: Analytical Hillshading, Slope, Aspect, Cross-Sectional Curvature, Longitudinal Curvature, Convergence Index, Flow Accumulation, Topographic Wetness Index, LS Factor, Channel Network Base Level, Vertical Distance to Channel Network, Valley Depth, Relative Slope Position.

Com as camadas erosividade, erodibilidade e fator_LS, obteve-se, por meio da equação (01) o mapa de PNE/EUPS (Figura 2). Do qual se extraiu as amostras de PNE (variável resposta).

As informações dos pixels das covariáveis ambientais e do PNE/EUPS foram extraídas para o arquivo com os 97 pontos de amostragem, que posteriormente, foi salvo no formato de planilha (csv) e carregado no software WEKA para gerar a equação de regressão e realizar a análise exploratória dos dados. A opção pelo software WEKA, nesta etapa, foi somente pela facilidade encontrada nos procedimentos para este fim e manipulação de dados. 


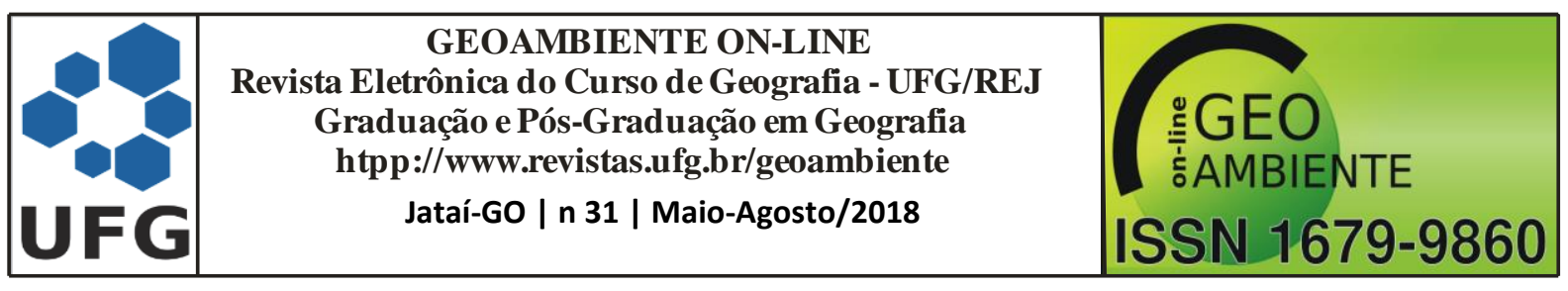

Figura 2. Mapa do PNE ( $\mathrm{t}$ ha $-^{1}$ ano-$^{-1}$ ) aplicando os fatores R.K.LS da EUPS.

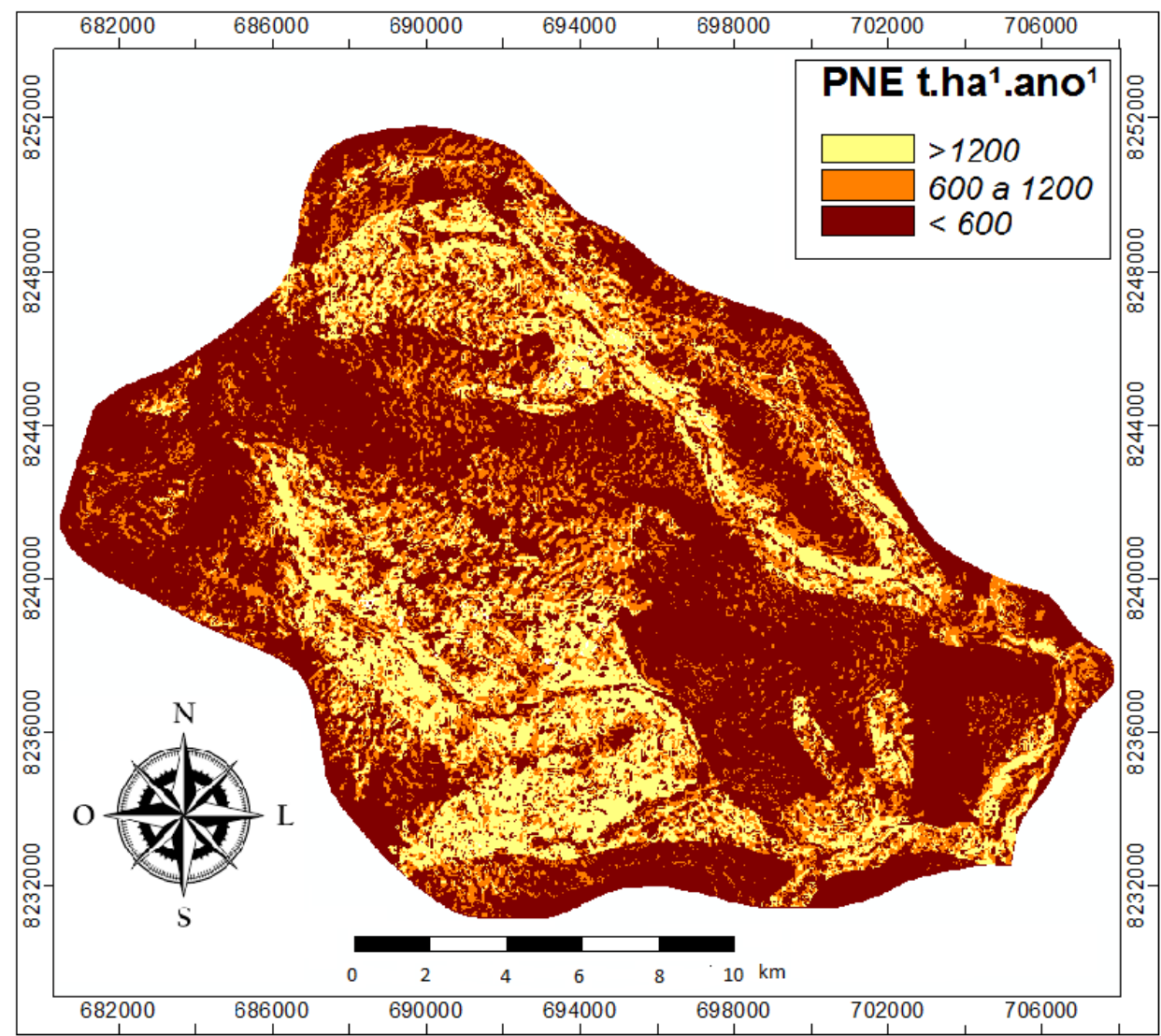

Como o WEKA descarta automaticamente as variáveis que não contribuem estatisticamente para a precisão do modelo, desta forma, a equação resultante desse procedimento contém apenas oito variáveis preditoras que cumpriram os pressupostos da regressão, assim, tornou possível modelar o PNE/RLM como função das covariáveis ambientais, com a Eq. (4):

$P N E \_R L M=(-48.292)+(-3.9702 *$ DEM $)+(381.1669 *$ LS.Factor $)+(3.8635 *$ Channel.Network.Base.Level) + (90.6723* Topographic.Wetness.Index $)+(676637.4808 *$ Cross.Sectional.Curvature $)+(-4532.2602 *$ Normalized.Difference.Vegetation.Index $)+$ $(0.000026 *$ Flow.Accumulation $)+(0.8752 *$ L8maio16B2..1.) $+(-0.7523 *$ L8maio16B4..1.). 


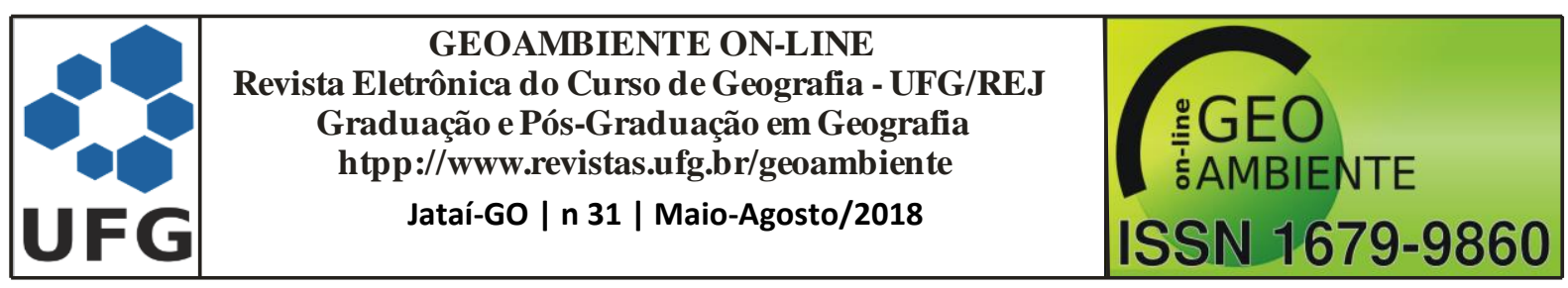

A regressão tem por objetivo estudar a relação entre duas ou mais variáveis buscando uma curva que descreva essa relação para fins de estimativa. Além da equação de regressão, outros resultados também são importantes e contribuem para o entendimento do comportamento das variáveis. Um deles é o valor do coeficiente de correlação (r) que foi de 0,49, indicando que há um moderado grau de associação entre as variáveis. O coeficiente de determinação $\left(\mathrm{r}^{2}\right)=0,24$, indica que $24 \%$ da variação do PNE na bacia são explicadas pela variação das covariáveis ambientais.

A análise de variância para a regressão (ANOVA) apresentada na Tabela 2 permite concluir que, ao nível de significância de 5\%, as covariáveis ambientais influenciam o potencial natural a erosão, visto que $\mathrm{F}$ calculado $=3,095$ é maior que $\mathrm{F}$ tabelado $=2,004$.

Depois de confirmado estatisticamente pela ANOVA a relação existente entre as variáveis (Tabela 2), submeteu-se, os dados da variável resposta, das covariáveis ambientais de saída do modelo, dos valores preditos e dos resíduos a uma análise exploratória, cujo, resultados são apresentados nos histogramas da Figura 3.

Tabela 2. Análise de variância para a regressão (ANOVA).

\begin{tabular}{lllll}
\hline & Gl & SQ & MQ & F \\
\hline Regressão & 9 & 12391105,36 & 1376789,485 & $3,09528^{*}$ \\
\hline Resíduo & 87 & 38697822,2 & 444802,554 & \\
\hline Total & 96 & 51088927,56 & & \\
\hline
\end{tabular}

* Significativo ao nível de 5\% de probabilidade.

Os histogramas mostram a distribuição de frequência desses conjuntos de dados. No histograma referente à amostra (PNE/EUPS) nota-se uma distribuição assimétrica-direita e que a maioria das amostras apresentam valores inferiores a $600 \mathrm{t} \mathrm{ha}^{-1}$ ano- $^{-1}$. Enquanto a maioria dos valores de PNE/RLM situa-se entre 275 a 850 t ha- ${ }^{1}$ ano- $^{1}$ e, os erros estão distribuídos aparentemente de forma normal. O valor mínimo e o máximo dos resíduos foram respectivamente, -2432,664 a 1366,859, a média próxima de 0,0 e desvio padrão 634,906. 


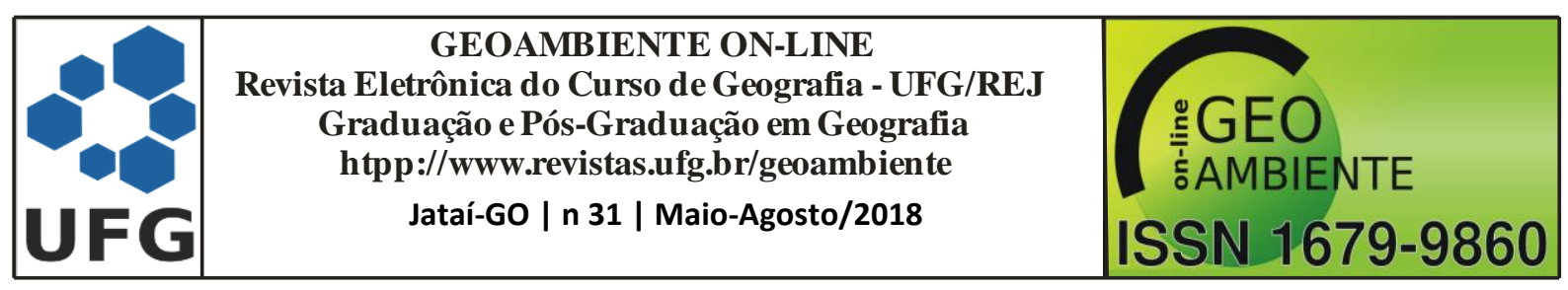

Figura 3. Histogramas das amostras PNE (resposta), das covariáveis ambientais (regressoras), e dos valores preditos e resíduos do modelo.

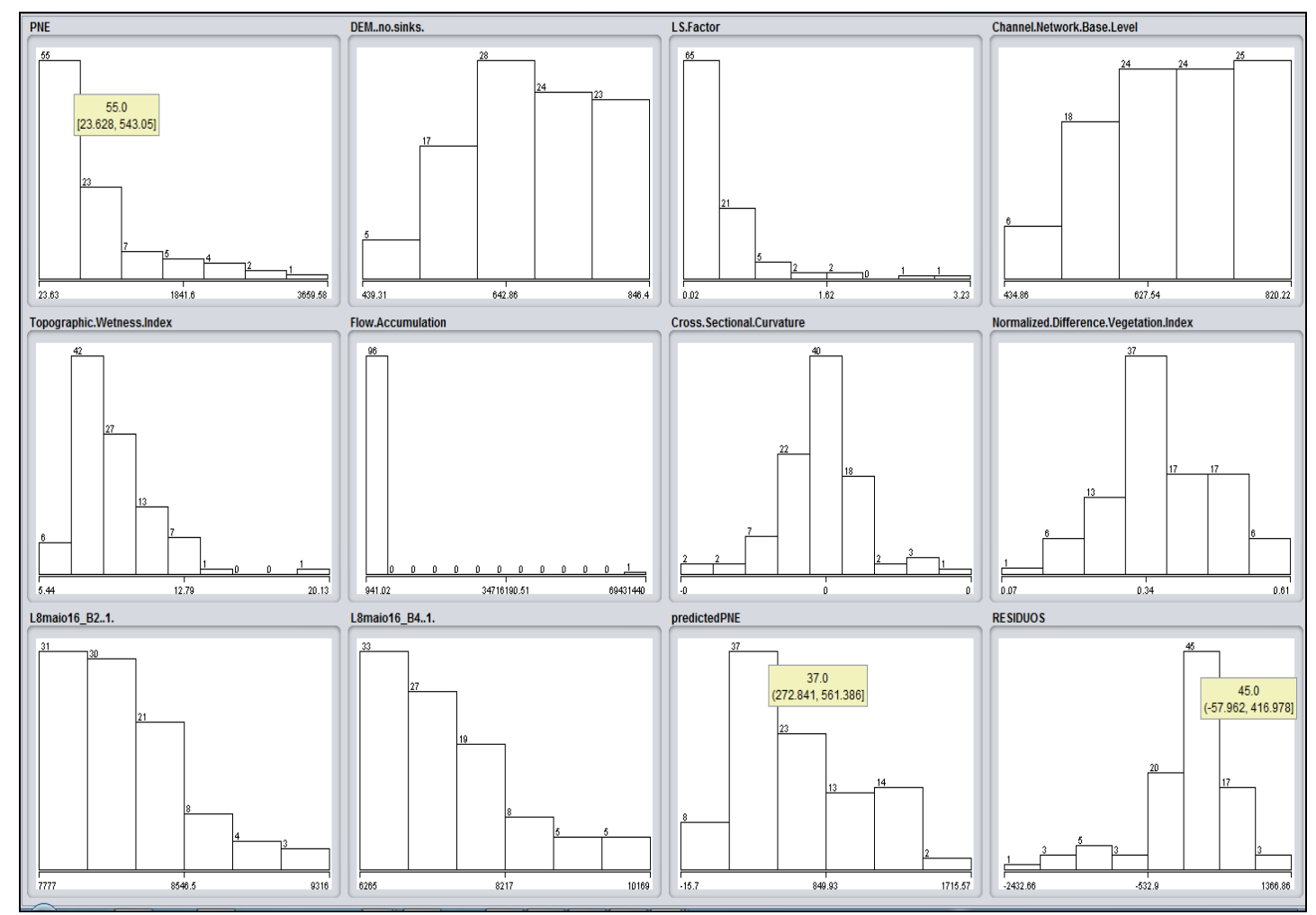

Em relação aos valores preditos, comparando-o com as amostras, verifica-se que valores mais altos foram subestimados e valores mais baixos sobreestimados.

Após gerar a equação foi realizada a modelagem da tendência local espacial dos resíduos e, assim, pode-se ajustar e selecionar o modelo espacial de semivariograma para melhor estimativa do PNE/RLM (Figura 4).

Uma das funções mais utilizadas para determinar a dependência espacial de variáveis é a função de semivariância que gera o semivariograma.

Os ajustes e a krigagem dos resíduos foram executados no RStudio. Nesta etapa foram testadas diferentes opções para obter o "melhor" modelo de variograma ajustado, inclusive foram alterados o tamanho e o número de lags para a construção do variograma empírico e feita a troca do modelo de variograma ajustado e do método de ajuste. Também efetuou-se o 


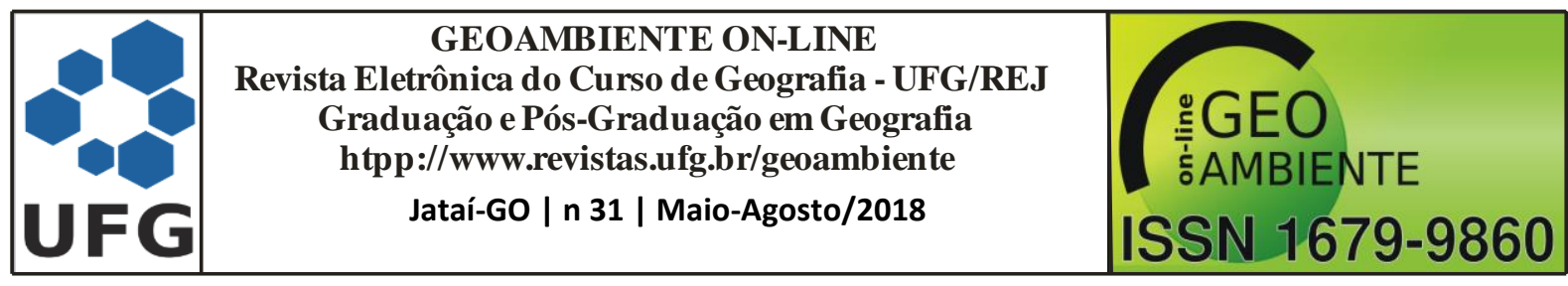

ajuste do patamar, o efeito pepita e o alcance dos dados, resultando no semivariograma mostrado na Figura 4.

Figura 4. Semivariograma ajustado ao modelo esférico.

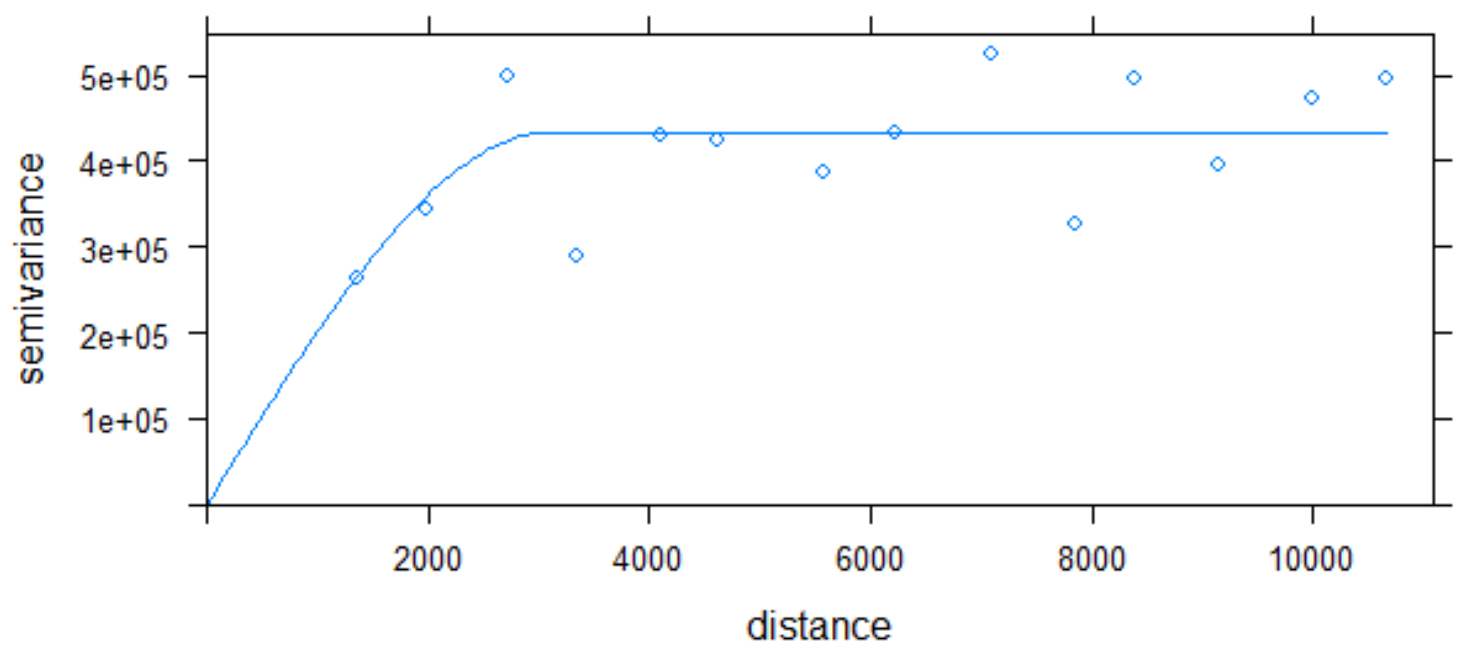

O nível de dependência entre as variáveis é representado pelo semivariograma, a partir dele infere-se, que existe uma forte dependência espacial, uma vez que, o valor de contribuição é pouco inferior ao valor do seu patamar. O patamar de 432882.4 é o valor do semivariograma onde se considera que, a partir desse ponto não existe mais dependência espacial entre as amostras, porque a variância da diferença entre pares de amostras torna-se invariante com a distância.

O alcance refere-se à distância em que as amostras de PNE estão correlacionadas espacialmente, no caso, ocorre próximo de 3093,772m, conforme dados de entrada e ajustes realizados no programa RStudio. Após o ajuste do semivariograma foi realizada a krigagem ordinária dos resíduos, possibilitando gerar o mapa apresentado na Figura 5.

$\mathrm{Na}$ distribuição espacial dos resíduos (Figura 5) verifica-se facilmente a influência de determinados pontos amostrais, característica inerente à krigagem (VASQUES et. al., 2013).

Para produzir o mapa final com valores preditos, conforme metodologia proposta, apoiado em álgebra de mapas, usando a calculadora do SAGA foi aplicado o modelo de regressão linear múltipla Eq. (2). 


\begin{tabular}{|c|c|c|}
\hline & $\begin{array}{c}\text { GEOAMBIENTE ON-LINE } \\
\text { Revista Eletrônica do Curso de Geografia - UFG/REJ } \\
\text { Graduação e Pós-Graduação em Geografia } \\
\text { htpp://www.revistas.ufg.br/geoambiente } \\
\text { Jataí-Go | n } 31 \text { | Maio-Agosto/2018 }\end{array}$ & $\begin{array}{c}\text { ISEN } \\
\text { G }\end{array}$ \\
\hline
\end{tabular}

Figura 5. Mapa de krigagem ordinária dos resíduos da regressão linear múltipla de PNE em t.ha- ${ }^{1}$ ano- ${ }^{-1}$.

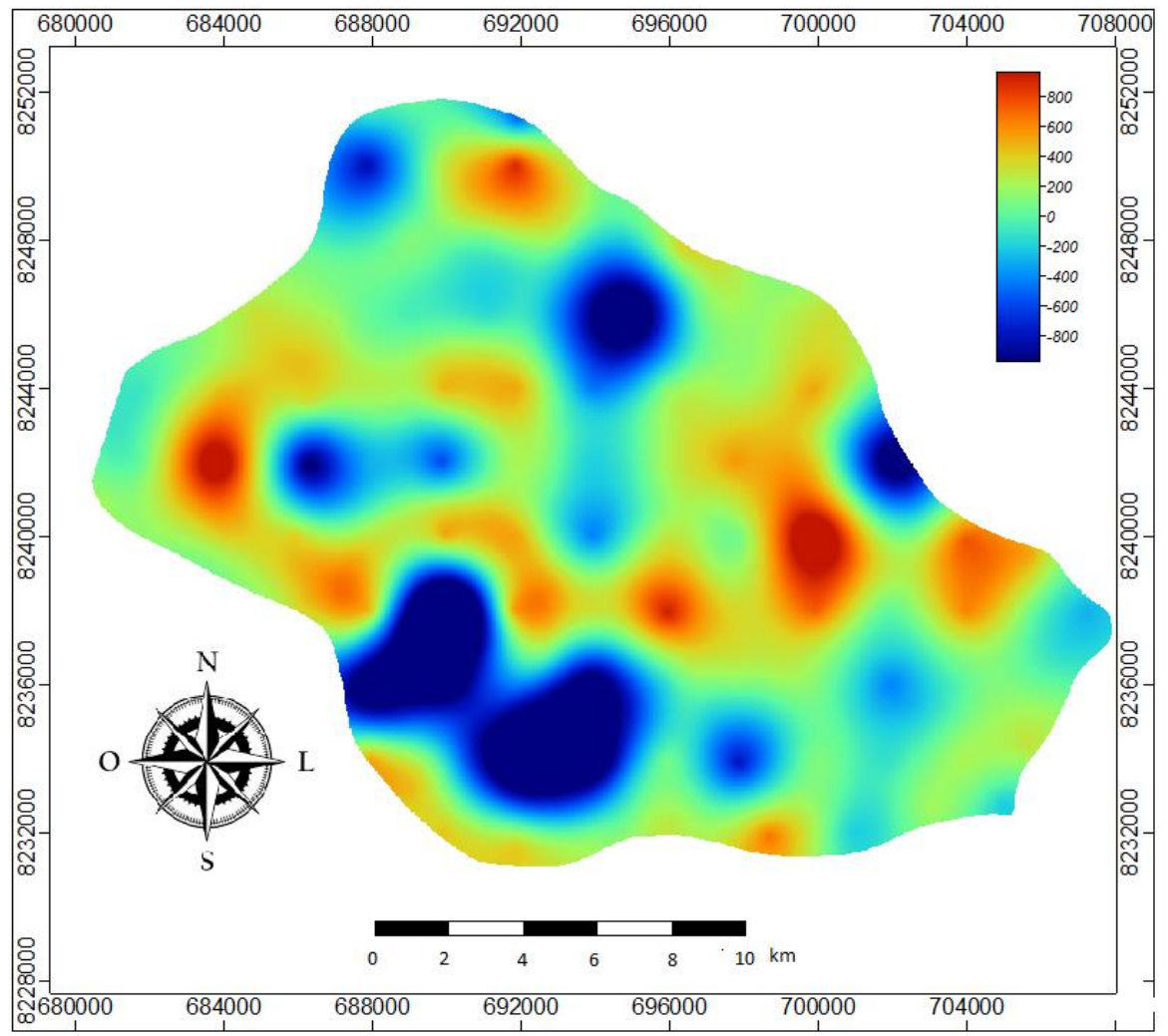

Este procedimento, denominado modelagem de tendência global, gerou um novo mapa que em seguida foi somado ao mapa da Figura 5 contendo os resultados de krigagem dos resíduos da regressão (krigagem ordinária). Sendo assim, por meio de métodos e técnicas empregadas no mapeamento digital de solos foi possível construir por meio de regressãokrigagem o novo mapa de PNE/RLM mostrado da Figura 6.

Comparando os dois mapas nas Figuras 2 e 6, pode-se quantificar, verificar e analisar a distribuição espacial do potencial natural a erosão na bacia.

O valor médio do potencial natural à erosão na bacia extraído do mapa gerado pelo método EUPS foi de 714,8 $\mathrm{t} \mathrm{ha-}^{1}$ ano- $^{-1}$, enquanto o valor médio extraído do mapa produzido por meio de regressão-krigagem foi de $757,4 \mathrm{t} \mathrm{ha-}^{-1}$ ano- $^{1}$. 


\begin{tabular}{|c|c|c|}
\hline & $\begin{array}{c}\text { GEOAMBIENTE ON-LINE } \\
\text { Revista Eletrônica do Curso de Geografia - UFG/REJ } \\
\text { Graduação e Pós-Graduação em Geografia } \\
\text { htpp://www.revistas.ufg.br/geoambiente } \\
\text { Jataí-Go | n } 31 \text { | Maio-Agosto/2018 }\end{array}$ & $\begin{array}{c}\text { :GEO } \\
\text { ISAMBIENTE } \\
\text { ISSN 1679-9860 }\end{array}$ \\
\hline
\end{tabular}

Figura 6. Mapa de PNE (t ha- ${ }^{1}$ ano-${ }^{1}$ ) gerado utilizando regressão-krigagem.

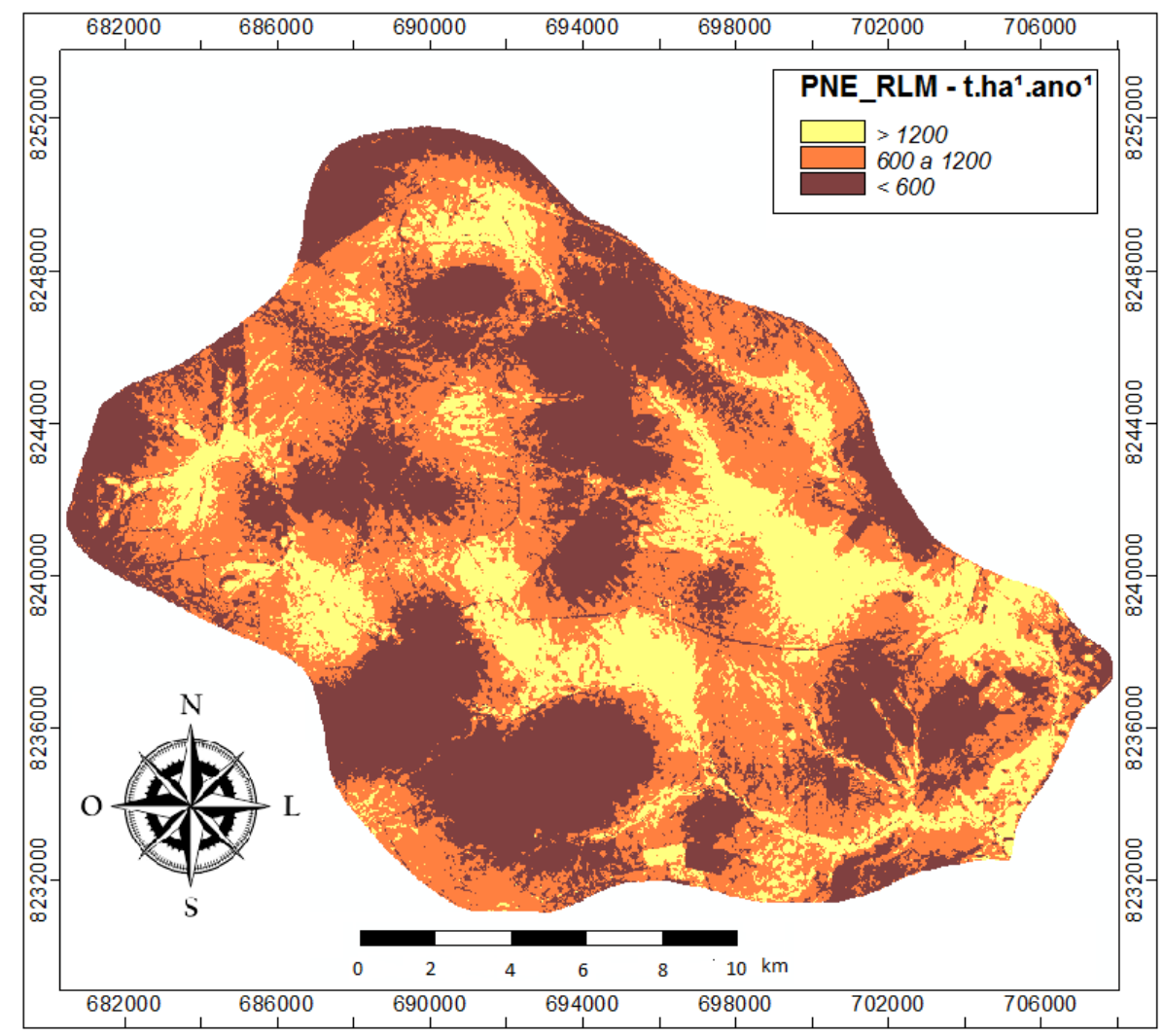

Esses valores são superiores aos verificados por Galdino et al. (2004) na bacia do Alto Taquari, que abrange o sudeste de Mato Grosso, onde o valor médio do potencial de perda de solos é de 555,6 t ha-1 ano-1, entretanto, se considerarmos apenas o trecho dessa bacia sobre território matogrossensse, este valor é de 587,9 t ha- ${ }^{1}$ ano- ${ }^{1}$. No sul do Piauí, também em área de ocorrência de vegetação Cerrado e com classes pedológicas semelhantes, Moares e Sales (2017) verificaram o predomínio de baixo potencial a erosão na bacia hidrográfica do alto Gurguéia, a média de PNE nesse local é de 373,4 t ha- ${ }^{1}$ ano- ${ }^{1}$.

No mapa confeccionado pelo método tradicional (Figura 2) ocorre predomínio de áreas com baixo potencial natural a erosão, ou seja, em 205,37 km² da bacia o PNE é inferior a 600 t ha- $^{1}$ ano-$^{1}$. No mapa produzido por regressão-krigagem (Figura 6) há um equilíbrio quantitativo na distribuição das áreas com baixo e moderado potencial natural a erosão, ou seja, em 134,88 km² o PNE é inferior a $600 \mathrm{t} \mathrm{ha-}^{1}$ ano-$^{-1}$ e em 141,73 $\mathrm{km}^{2}$ da bacia o PNE varia entre 600 até $1200 \mathrm{t} \mathrm{ha-}^{1}$ ano-$\left.^{1}\right)$. 


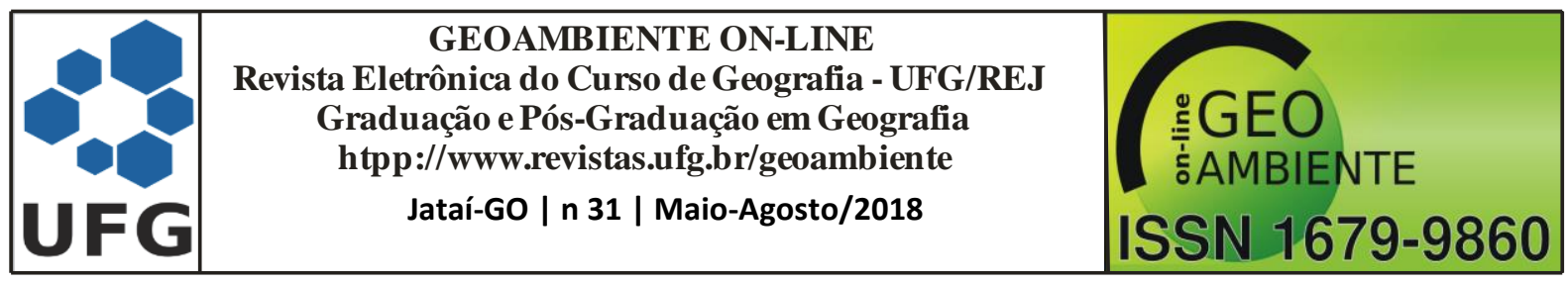

Silva e Mercante (2014) verificaram que a maior parte $(59,19 \%)$ do Estado do Paraná possui baixo potencial natural de erosão, valores inferiores a $500 \mathrm{t} \mathrm{ha-}^{1}$ ano-1 $^{1}$ e que cerca de $30 \%$ do Estado apresenta PNE entre 500 a $1500 \mathrm{t} \mathrm{ha}^{-1}$ ano- $^{-1}$ e pouco mais de $10 \%$ do Estado apresenta potencial natural a erosão superior a $1500 \mathrm{t} \mathrm{ha-}^{-1}$ ano-1.

Os valores de PNE, tanto no mapa EUPS, quanto no mapa produzido por regressãokrigagem, as áreas com potencial acima de $1200 \mathrm{t} \mathrm{ha-}^{-1}$ ano-1 ${ }^{-1}$ e equivalem e ocupam menores porções de terras no interior da bacia hidrográfica $\left(62,83 \mathrm{~km}^{2}\right.$ no mapa produzido por regressão-krigagem e $63,94 \mathrm{~km}^{2}$, no caso do mapa produzido pela EUPS).

Os resultados aqui apresentados, nos dois casos, apresentam as mesmas tendências de Galdino et al. (2004), Silva e Mercante (2014) e Oliveira et al. (2015), ou seja, predominância de classes de PNE de fraco a moderado e em menor escala a ocorrência de PNE forte a muito forte.

A verificação da correspondência espacial entre os mapas (Figuras 2 e 6) feita de forma visual não possibilitou obter informações precisas das áreas onde os valores preditos são semelhantes ao da amostra, por isso, no próprio SAGA, foi gerado o Scatterplot (Figura 7), por essa técnica observa-se a dispersão dos dados nos dois mapas e a correspondência dos valores de pixel entre ambos.

A transformação dos dados da Figura 7 em tabela permitiu efetuar uma análise de Cluster, e assim, verificar estatisticamente no WEKA a existência de três agrupamentos. O primeiro apresentou maior diferença de médias, 2.204,89 $\mathrm{t} \mathrm{ha-}^{-1}$ ano- $^{1}$ (PNE-EUPS) e 672,04 t ha- $^{1}$ ano- $^{-1}$ (PNE_RLM).

O segundo agrupamento (ocupando $50 \%$ da área e menor diferença de médias) com valor de 406,68 $\mathrm{t} \mathrm{ha-}^{-1}$ ano-$^{-1}$ (PNE-EUPS) e 430,78 $\mathrm{t} \mathrm{ha-}^{-1}$ ano-$^{-1}$ (PNE_RLM). O terceiro grupo com média de 505,30 $\mathrm{t} \mathrm{ha}^{-1}$ ano- $^{1}$ (PNE-EUPS) e 1.259,78 $\mathrm{t} \mathrm{ha-}^{-1}$ ano- $^{1}$ (PNE_RLM). 


\begin{tabular}{|c|c|c|}
\hline & $\begin{array}{c}\text { GEOAMBIENTE ON-LINE } \\
\text { Revista Eletrônica do Curso de Geografia - UFG/REJ } \\
\text { Graduação e Pós-Graduação em Geografia } \\
\text { htpp://www.revistas.ufg.br/geoambiente } \\
\text { Jataí-Go | n } 31 \text { | Maio-Agosto/2018 }\end{array}$ & $\begin{array}{c}\text { ISEN } \\
\text { G }\end{array}$ \\
\hline
\end{tabular}

Figura 7. Scatterplot PNE_RLM x PNE_EUPS (RKLS)

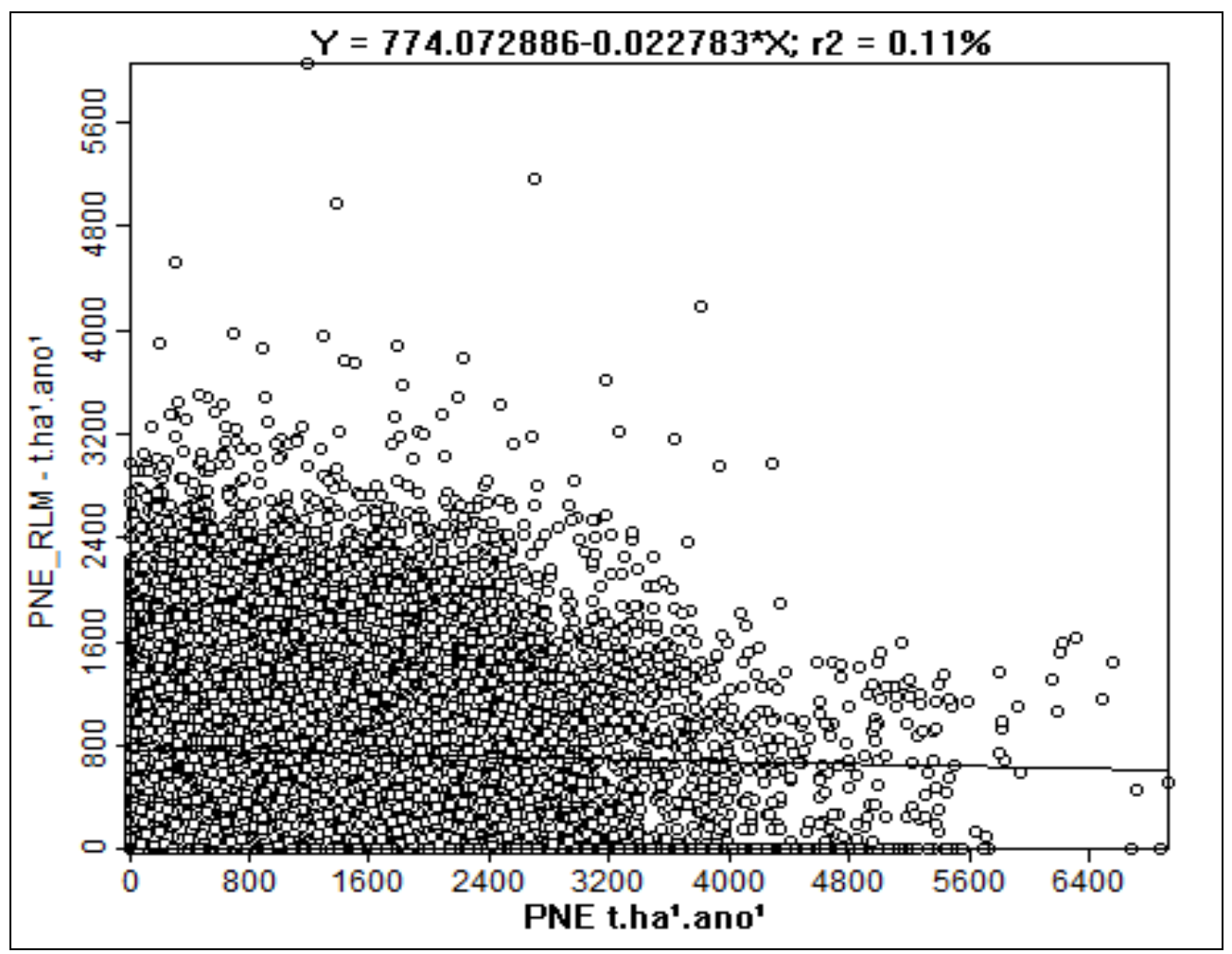

\section{Conclusões}

Com uso de métodos e técnicas empregadas no mapeamento digital de solos (MDS) foi possível construir por meio de regressão-krigagem um novo mapa do Potencial Natural a Erosão. Nesse mapa verifica-se um equilíbrio quantitativo na distribuição das áreas com potencial natural a erosão menores que 600 t.ha- $^{1}$.ano- ${ }^{1}$ e áreas de 600 a 1200 t.ha- ${ }^{1}$.ano- ${ }^{1}$ $\left(134,88 \mathrm{~km}^{2}\right.$ e $141,73 \mathrm{~km}^{2}$, respectivamente).

Para o perfeito entendimento dos processos erosivos é fundamental o conhecimento das propriedades dos solos, pois, estas propriedades atuam em conjunto e definem o grau de suscetibilidade à erosão. Entre as propriedades dos solos, a textura que representa a combinação dos teores de areia, silte e argila, é a que pode interferir em maior ou menor escala no desencadeamento dos processos erosivos. No entanto, os resultados aqui demonstrados, constituem em informações que permitem reavaliar o uso do solo e assim, caso necessário, redirecionar as atividades no local. Mas, não sem antes confirmar com novos 


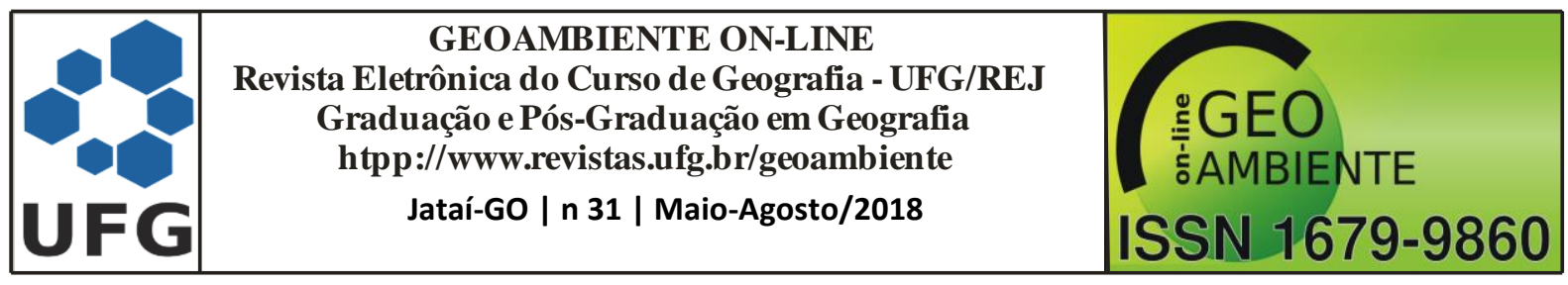

estudos se essa abordagem é capaz de gerar resultados similares ou melhores que os encontrados com aplicação da metodologia tradicional.

\section{Referências}

ACCIOLY, L. J. O.; ARAUJO, A. M.; SIlvA, A. B.; LOPES, H. L.; SIlVA, E. A. Estimativas do Potencial Natural de Erosão das Terras da Bacia do Rio Ipojuca-PE. Teresina. In: Reunião Brasileira de Manejo e Conservação do solo e da água, 28., 2010, Teresina. Anais... Terezina: Empresa Brasileira de Pesquisa Agropecuária - Embrapa, 2010. p. 1- 4.

ANDRADE, S. F.; MENDONÇA-SANTOS, M. L. Predição da fertilidade do solo do polo agrícola do Rio de Janeiro por meio de modelagem solo x paisagem. Pesquisa Agropecuária Brasileira, v. 51, n. 9, p. 1386-1395. 2016.

BACA, J. F. M.; VASQUES, G. de M.; DART, R. de O.; BREFIN, M. de L. M. S.; OLMEDO, G. F. Capacitação em Mapeamento Digital de Solos. Parte 1 - Cursos Presenciais e à Distância para Técnicos da América Latina e Caribe, In: Congresso Brasileiro de Ciência do Solo, 34., 2013, Florianópolis. Anais... Florianópolis: Sociedade Brasileira de Ciência do Solo, 2013.

BERTONI, J.; LOMBARDI NETO, F. Conservação do solo. 5 ed. São Paulo: Editora Ícone, 2005. 355p.

Brasil. Ministério do Meio Ambiente, dos Recursos Hídricos e da Amazônia Legal (Brasília, DF). Plano de Conservação da Bacia do Alto Paraguai (Pantanal) - PCBAP: análise integrada e prognóstico da Bacia do Alto Paraguai. Brasília, v.3, anexos. Programa Nacional do Meio Ambiente. Projeto Pantanal. 1997.

BUENO, C.R.P. E STEIN, D.P. Potencial natural de erosão na região de Brotas, Estado de São Paulo, Acta Scientarium Agronomy, Maringá, v.26, nº 1.p. 1-5, 2004.

CAMPOS, M.C.C. Relação solo-paisagem: conceitos, evolução e aplicações. Ambiência, Guarapuava - PR, v. 8 n. 3, p.963-982, 2012.

CHRISTOFOLETTI, A. Geomorfologia. $2^{\circ}$ ed. São Paulo: Edgard Blücher, 1980. 


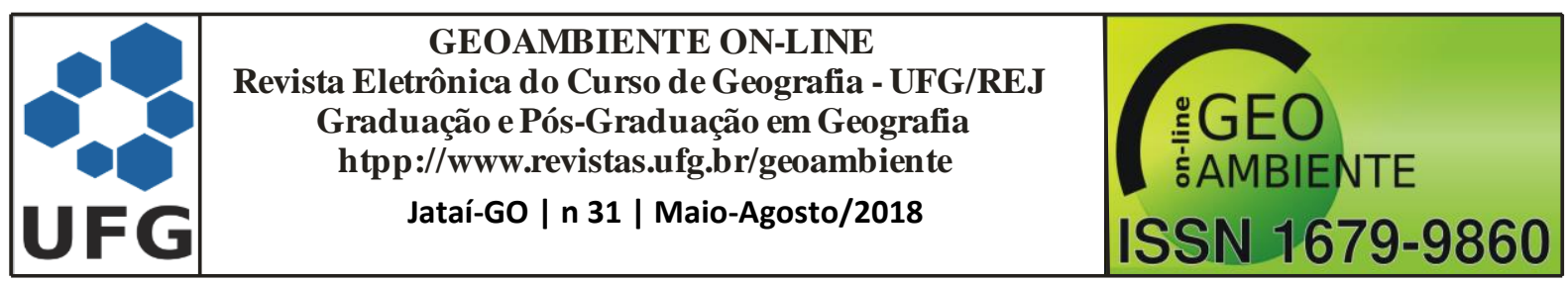

EMBRAPA, Centro Nacional de Pesquisa de Solo (Rio de Janeiro, RJ). Sistema Brasileiro de Classificação de Solos. Rio de Janeiro, 1999.

FONSECA NETO; L.; SALOMÃO; F.X. DE T.; CASTRO JÚNIOR P. R. de; Conflitos de uso e controle erosivo em área representativa da produção agrícola intensiva no Planalto dos Guimarães, MT, Revista Agricultura Tropical, v.8, p. 76-99, 2005.

FUNDAÇÃO ESTADUAL DE MEIO AMBIENTE. Estudo Integrado da Bacia do rio Tenente Amaral uma Proposta de Zoneamento Ambiental. (FEMA - PRODEAGRO - BIRD), Cuiabá-MT, 1999.

HASUI, Y. Compartimentação Geológica do Brasil. In: Geologia do Brasil. Organizado por Yociteru Hasui; Celso Dal Ré Carneiro; Fernando Flávio Marques de Almeida; Andrea Bartorelli; - São Paulo: Beca, 2012, p. 112-122.

GALDINO, S.; VIEIRA, L.M.; PADOVANI, C.R.; SORIANO, B.M.A.; RISSO, A.; MELO, E.C.; ALMEIDA JUNIOR, N.. (2004). "Erosão potencial laminar hídrica na bacia do altoTaquari”. Revista Brasileira de Recursos Hídricos, v.9, n.2, p. 125-133, 2004.

LACERDA FILHO, J.V. Geologia e Recursos Minerais do Estado de Mato Grosso. Org. Joffre Valmório de Lacerda Filho, Waldemar Abreu Filho, Cidney Rodrigues Valente, Cipriano Cavalcante de Oliveira e Mário Cavalcanti Albuquerque. Esc. 1:1.000.000. Goiânia: CPRM, (Convênio CPRM/SICME). 200p. il.; + mapas. 2004.

McBRATNEY, A. B.; ODEH, I. O. A.; BISHOP, T. F. A..; DUNBAR, M. S.; SHATAR, T. M.. An overview of pedometric techniques for use in soil survey, Geoderma, Amsterdam, v. 97, n. 3-4, p. 293-327, 2000.

McBRATNEY, A. B.; MENDONÇA-SANTOS, M. L.; MINASNY, B.. On digital soil mapping, Geoderma, v. 117, p. 3-52, 2003.

MENDONÇA-SANTOS, L. M. \& SANTOS, H. G. Mapeamento digital de classes e atributos de solos - métodos, paradigmas e novas técnicas. Empresa Brasileira de Pesquisa Agropecuária - EMBRAPA, Rio de Janeiro, Documentos 55, 2003. 19p. 


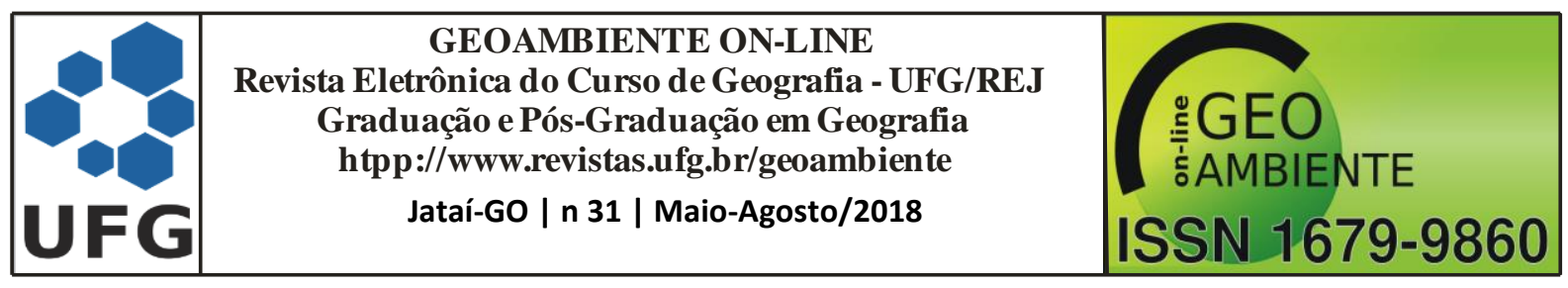

SILVA B. B. da, MERCANTE. E.; Mapeamento por técnicas de geoprocessamento do potencial natural de erosão (PNE) para o Estado do Paraná. In: Congresso Brasileiro de Engenharia Agrícola - CONBEA 2014, 43., 2014, Campo Grande. Anais... Campo Grande: Sociedade Brasileira de Engenharia Agrícola, 2014.

MORAIS, R. C. de S.; SALES, M. Celina C. L. Estimativa do Potencial Natural de Erosão dos Solos da Bacia Hidrográfica do Alto Gurguéia, Piauí-Brasil, com uso de Sistema de Informação Geográfica, Caderno de Geografia, Belo Horizonte - MG, v. 27, n. 1, p. 84-105, 2017. Disponível em: <http://200.229.32.55/index.php/geografia/article /view/16193>. Acesso em: 18 Jan. 2018.

NIMER, E. Climatologia do Brasil. 2. ed. Rio de Janeiro: IBGE, 1989. 421p.

OLIVEIRA, F.G; SERAPHIM, O. J.; BORJA, M. E. L. Estimativa de perdas de solo e do potencial natural de erosão da bacia de contribuição da microcentral hidrelétrica do Lageado, Botucatu - SP, Energia na Agricultura, Botucatu, vol. 30, n.3, p.302- 309, 2015.R

CORE TEAM. R: a language and environment for statistical computing. Viena: $\mathrm{R}$ Foundation for Statistical Computing. Disponível em: <http://cran.r-project.org>. Acesso em 18 dez. 2016.

RSTUDIO. RStudio: integrated development environment for R. Boston: RStudio. Disponível em: <http://www.rstudio.com>. Acesso em 18 dez. 2016.

SAGA USER GROUP ASSOCIATION. System for Automated Geoscientific Analyses (SAGA). Göttingen: Department for Physical Geography, University of Göttingen. Disponível em: <http://www.saga-gis.org>. Acesso em 18 dez. 2016.

SILVA, A.M.; H.E. SCHULZ e P.B. CAMARGO. Erosão e hidrossedimentologia em bacias hidrográficas. São Carlos, Editora Rima, 2003. 140p.

TEN CATEN, A.; DALMOLIN, R. S. D.; PEDRON, F. A.; MENDONÇA-SANTOS, M. de L.; Estatística multivariada aplicada à diminuição do número de preditores no mapeamento digital do solo. Pesquisa Agropecuária Brasileira, Brasília, v. 46, n. 5, p. 554-562. 2001. 


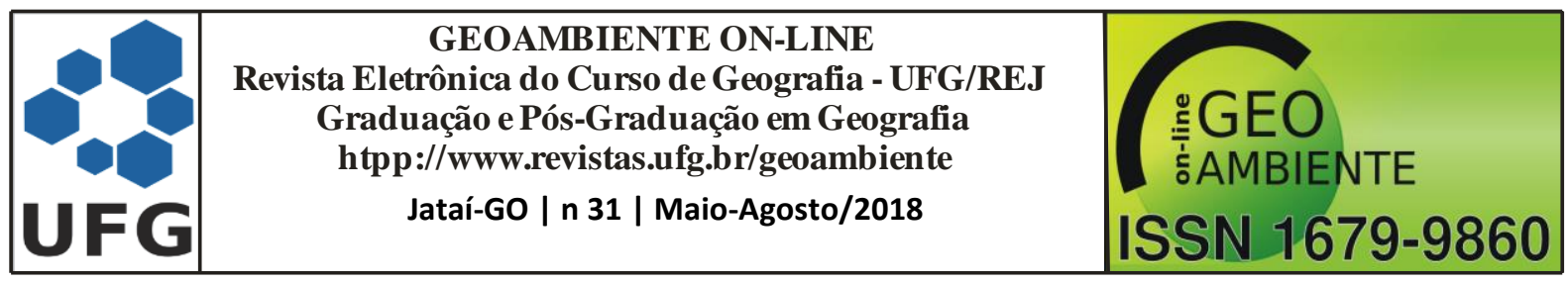

VASQUES, G. M.; DART, R.O. ; BACA, J. F. M. ; OLMEDO, G. F. ; BREFIN, M.L.M.S. Capacitação em mapeamento digital de solos. Parte 2. Estudo de caso: carbono do solo em Campos dos Goytacazes, RJ. In: Congresso Brasileiro de Ciência do Solo, 34., 2013, Florianópolis. Anais... Florianópolis: Sociedade Brasileira de Ciência do Solo, 2013.

WISCHMEIER WH, SMITH DD. Predicting rainfall erosion losses: A guide to conservation planning. Washington: United States Department of Agriculture; 1978. 